\title{
Study of novel high-density panels based on negative space welding technology with cells cut by different techniques
}

\author{
Hao Zhuang ${ }^{1, *}$, Guoping Huang ${ }^{1}$, Yashuai Jiang ${ }^{1}$, Xueliang Bai ${ }^{1}$, Guan Sun $^{1}$, and Jingnan \\ $\mathrm{Li}^{1,2}$ \\ ${ }^{1}$ CECEP Solar Energy Technology (Zhenjiang) Co. Ltd, Zhenjiang, China \\ ${ }^{2}$ CECEP Solar Energy Co. Ltd, Beijing, China
}

\begin{abstract}
Negative space welding technology (NSWT) is a newly adopted advanced technology for high-density solar panels. The benefit of this technology is its capability to improve the efficiency of panels. However, the introduction of a new technology or material may affect the original reliability. Some unexpected power loss may occur during its operation in different environments. Hence, in this work, damp heat (DH), thermal cycle (TC), UV irradiation and humidity freezing (HF) tests were utilized to evaluate the weatherability of NSWT-based panels fabricated with silicon cells cut by two different techniques. It is suggested by our results that these new panels with negative space between cells have good weatherability both in damp heat, dry heat and UV irradiation condition. The novel low-damage laser-induced cutting technique is beneficial for the improvement of module reliability.
\end{abstract}

\section{Introduction}

Technology of solar panels is progressing rather quickly [1]. The typical structure of a single-glass solar panel is as follows, glass/EVA/cell/EVA/backsheet. For a conventional module, cells are connected with a space of around $2 \mathrm{~mm}$ to form cell strings. Spurred by the demand for modules with even higher efficiency, recently, high-density interconnection technology has occurred. Benefited from this technology, cell space in a string can be decreased from $\sim 2 \mathrm{~mm}$ to $\sim 0.5 \mathrm{~mm}$ or even smaller.

To further increase module efficiency, negative space welding technology (NSWT) has been employed in solar panels quite recently. The application of this technology can decrease the inactive area in a string. However, it might also affect the original weatherability of a panel.

The lifetime of a solar panel is highly correlated with the decay of its output power. Lots of external factors can lead to the decay of solar panels, such as mechanical load, large and frequent temperature change, UV irradiation and humid gas [2-6]. Degradation in power [7-10] could be triggered by those factors that cause electrode corrosion, encapsulant discoloration, delamination between layers, cell cracking, etc. UV often causes the decay

\footnotetext{
*Corresponding author: zhuanghao@cecsec.cn
} 
by the yellowing of polymeric encapsulants and the decay of silicon cells. Variation in temperature may generate internal stress as materials have different coefficients of thermal expansion (CTE), which may consequently lead to cracking of cells. Humid gas decays a panel via penetration through the polymeric backplate, which causes the finger corrosion.

Herein, the effects of various external factors on the decay extent of panels were considered. UV irradiation, thermal cycle, damp heat and humidity freezing tests were conducted to study the weatherability of NSWT-based panels. The output power under standard test condition was measured after each simulated test. It is verified by the results that these novel high-density modules have excellent weatherability in all these evaluated environments. The novel low-damage laser-induced cutting technique is beneficial for the improvement of module reliability. This work might offer a reference for the massive application of NSWT-based high-density panels.

\section{Methods}

Sample panels were made using standard production process with a typical glass/EVA/cell/EVA/backplate structure. Damp heat, thermal cycling and UV sequential tests were conducted based on the methods of IEC61215 standard using Hongze HH84, HT484 and Borui BR-PV-LID equipments, respectively. IEC61215 is an international standard generally adopted for the performance evaluation and qualification of solar panels. After each test, the power of sample panels was measured under STC $\left(25^{\circ} \mathrm{C}, 1000 \mathrm{~W} / \mathrm{m}^{2}\right.$, AM 1.5).

\section{Results and discussion}

Half cell technology has been widely applied in PV module products recently. The mechanical damage of half cells during the cutting process are varied for different cutting techniques, which may influence the weathering performance of this NSWT-based highdensity modules. If microcrackings are generated during the cutting process, the mechanical strength of the half cell would be much reduced. Therefore, in our work, two different cutting techniques were adopted to evaluate their difference on module reliability. Figure 1 shows the scheme of the negative space welding technology. The width of the stacking area is $\sim 0.5 \mathrm{~mm}$.

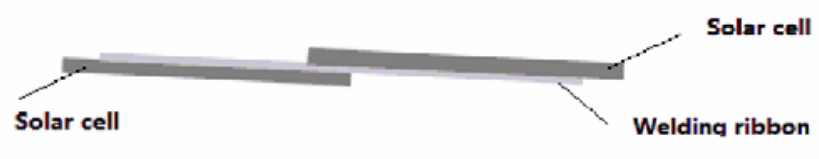

Fig. 1. Scheme of the negative space welding technology.

Electrical property of the NSWT-based panels was initially measured, see Table 1. Sample 5 to 7 were fabricated using conventional laser cutting technique. Sample 1 to 3 were fabricated using a novel low-damage laser-induced cutting technique. The average output power of sample 1 to 3 was $412.12 \mathrm{~W}$ and the average output power of sample 5 to 7 was $413.85 \mathrm{~W}$. The unexpected low power of sample 1 to 3 may be caused by the long-trip transportation of the half cells, which were cut in the other factory. 
Table 1. Initial property of NSWT-based high-density panels.

\begin{tabular}{cccccc}
\hline Panel & $\operatorname{Voc}(\mathrm{V})$ & $\operatorname{Vmp}(\mathrm{V})$ & $\operatorname{Isc}(\mathrm{A})$ & $\operatorname{Imp}(\mathrm{A})$ & $\operatorname{Pmp}(\mathrm{W})$ \\
\hline Sample 1 & 49.25 & 10.43 & 41.08 & 9.98 & 409.81 \\
Sample 2 & 49.35 & 10.44 & 41.19 & 10.02 & 412.59 \\
Sample 3 & 49.40 & 10.46 & 41.26 & 10.03 & 413.95 \\
Sample 5 & 49.43 & 10.45 & 41.31 & 10.01 & 413.60 \\
Sample 6 & 49.35 & 10.46 & 41.29 & 10.01 & 413.38 \\
Sample 7 & 49.46 & 10.47 & 41.37 & 10.02 & 414.58
\end{tabular}

To investigate the weatherability property of these new panels fabricated with cells cut by two different techniques in damp and heat condition, panel samples were put into a simulated environment $\left(85^{\circ} \mathrm{C} / 85 \%\right.$ R.H.). Damp heat (DH) test is known as an efficacious method to evaluate the panel's weatherability to resist long-time intrusion of humid gas. Figure 2 illustrates the electrical property tested under STC before and after DH. It could be noted that after $1000 \mathrm{~h}$ damp heat test, the power value of sample 2 decayed from $412.59 \mathrm{~W}$ to $408.82 \mathrm{~W}$, while that of sample 5 decayed from $413.60 \mathrm{~W}$ to $402.31 \mathrm{~W}$, demonstrating their good resistant property in damp heat climate. Panel fabricated with cells using the novel low-damage laser-induced cutting technique only degraded by $0.9 \%$, which is obviously lower than the one using the conventional laser cutting technique $(\sim 2.7 \%)$.

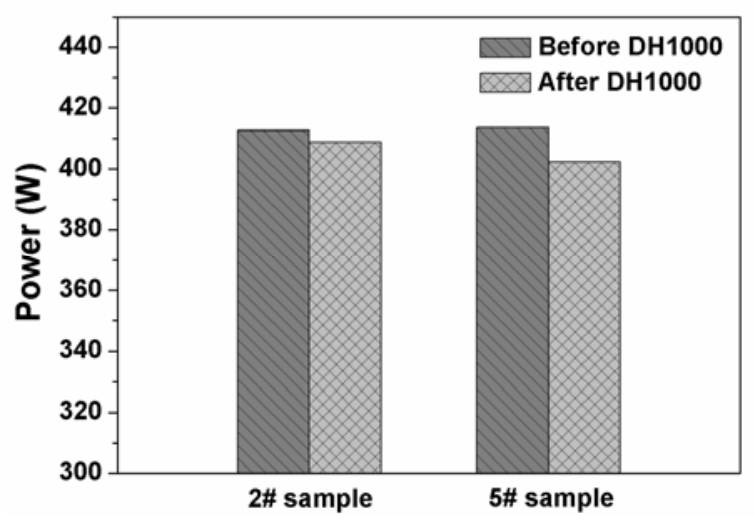

Fig. 2. Power measured before and after $1000 \mathrm{~h}$ DH test.

It is known that the characterization of dry heat climate is the big temperature variation at noon and midnight and low humidity. Thus, to inspect the weatherability of these new panels fabricated with cells cut by two different techniques in dry heat environment, sample 2 was put in a simulated temperature change environment for 200 cycles. The scope of temperature change is from $-40^{\circ} \mathrm{C}$ to $85^{\circ} \mathrm{C}$. Figure 3 shows the comparison of the panels' initial power and that after TC200 test. It could be noted that after the TC test, sample 1 with the novel low-damage laser-induced cutting technique showed no degradation in power and sample 6 only decayed a little from $413.38 \mathrm{~W}$ to $409.49 \mathrm{~W}$, demonstrating good dry heat withstand property of both modules and even better performance for the one using the novel low-damage laser-induced cutting technique. 


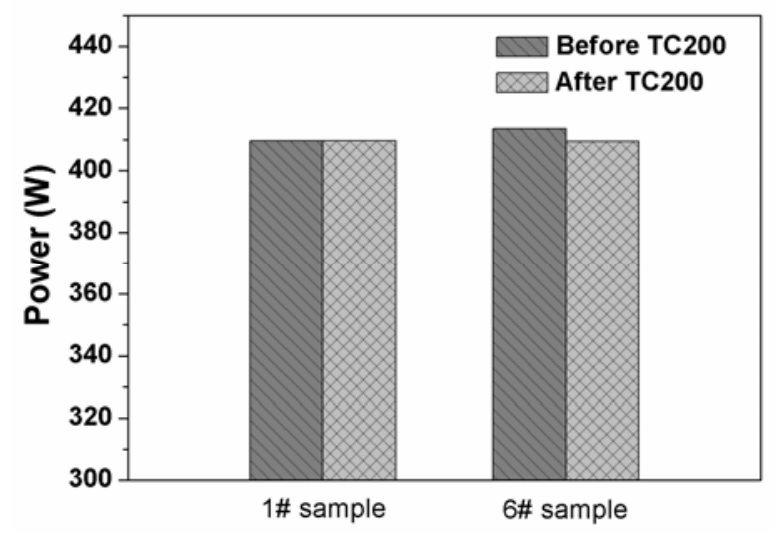

Fig. 3. Power measured before and after thermal cycle test.

To investigate these new panels' weatherability in integrated condition, sample panels underwent the UV15-TC50-HF10 sequential test. Figure 4 shows the panel power before and after the sequential test. After $15 \mathrm{kwh}$ UV test, sample 3 degraded from $413.95 \mathrm{~W}$ to $407.34 \mathrm{~W}$, implying their good UV resistant property. Afterwards, 50 times thermal cycle test was carried out, the power of sample 3 increased from $407.34 \mathrm{~W}$ to $411.24 \mathrm{~W}$. After TC50 test, humidity freezing test was conducted on the module. Thereafter the power value was tested to be $403 \mathrm{~W}$. Therefore, after this UV15-TC50-HF10 sequential test, the overall power decay is $10.95 \mathrm{~W}(-2.65 \%)$, implying good weatherability of this new panel in integrated condition. After $15 \mathrm{kwh}$ UV test, the power of sample 7 decayed from $414.58 \mathrm{~W}$ to $406.15 \mathrm{~W}$. Then TC50 test was conducted on the panel, the power of sample 3 increased from $406.15 \mathrm{~W}$ to $409.70 \mathrm{~W}$. Afterwards, humidity freezing test was conducted on the panel. The final power of the panel was tested to be $401.63 \mathrm{~W}$. Hence, after undergoing the sequential test, the overall power decay is $12.97 \mathrm{~W}(-3.12 \%)$, implying good weatherability in integrated condition.

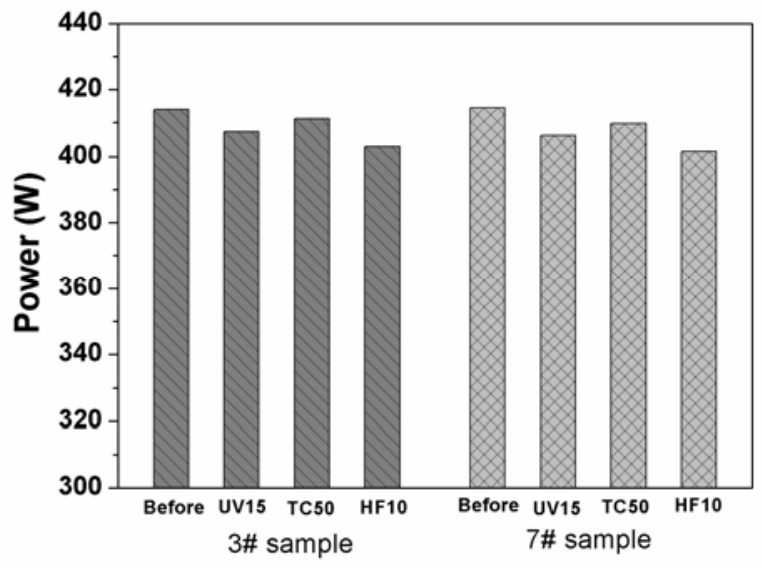

Fig. 4. Power measured before and after UV15-TC50-HF10 sequential test.

\section{Conclusion}

Negative space welding technology (NSWT) was applied into high-density panel products. To verify their weatherability, damp heat (DH), thermal cycle (TC), UV irradiation and humidity freezing (HF) test were conducted. The power decay of panels with conventional 
laser cutting technique is $2.7 \%$ after DH1000 test, $0.94 \%$ after TC200 and 3.12\% after UV15-TC50-HF10 sequential test. The power decay of panels with novel low-damage laser-induced cutting technique is $0.9 \%$ after DH1000 test, $0 \%$ after TC200 and $2.65 \%$ after UV15-TC50-HF10 sequential test. The achieved results verify that the novel high-density panels have excellent weatherability in damp heat, dry heat condition and after UV irradiation. Moreover, the novel low-damage laser-induced cutting technique is beneficial for the improvement of module reliability.

\section{Acknowledgements}

This work was financially supported by the study program cecep-zdkj-2019-002 and 19RD5 CECEP (Zhenjiang).

\section{References}

1. J. N. Roy. Solar Photovoltaic Technology, Sustainable Energy Technology and Policies, 21, (2017)

2. Shu-Tsung H, Wei-You L, Shih-Jui W, Environmental Factors for Non-uniform Dynamic Mechanical Load Test due to Wind Actions on Photovoltaic Modules, Energy Procedia, 50, 150, (2018)

3. Heman S and Thomas B, Experimental Study of the Degradation of Silicon Photovoltaic Devices under Ultraviolet Radiation Exposure, Journal of Solar Energy, Article ID 2473245, (2016)

4. Eder G, Voronko Y, Hirschl C, Ebner R, Ujvari G, Muhleisen W, Non-Destructive Failure Detection and Visualization of Artificially and Naturally Aged PV Modules, Energies, 11, 1053, (2018)

5. Alberto Pozza, Tony Sample, Crystalline silicon PV module degradation after 20 years of field exposure studied by electrical tests, electroluminescence, and LBIC, Progress in Photovoltaics, 24, (2016)

6. Yang Hu, Roger H. French, 5 - Degradation and Failure Mechanisms of PV Module Interconnects, Durability and Reliability of Polymers and Other Materials in Photovoltaic Modules, (2019)

7. Hoffmann S, Koehl M, Effect of humidity and temperature on the potential-induced degradation, Progress in Photovoltaics: Research and Applications 22, 173, (2014)

8. Taeko S, Corrosion mechanism analysis of the front-side metallization of a crystalline silicon PV module by a high-temperature and high-humidity test, Jpn. J. Appl. Phys. 59, 054001, (2020)

9. Zarmai T, Ekere N, Oduoza C F, Amalu H, Evaluation of thermo-mechanical damage and fatigue life of solar cell solder interconnections, Robotics and Computer-Integrated Manufacturing 47, 37, (2017)

10. Mahmoud Dhimish,Violeta Holmes, Bruce Mehrdadi, Mark Dales, The impact of cracks on photovoltaic power performance, Solar Energy Materials and Solar Cells, 2, (2017) 